\title{
Parthenolide induces apoptosis in colitis-associated colon cancer, inhibiting NF-кB signaling
}

\author{
SE LIM KIM ${ }^{1,2}$, YU CHUAN LIU ${ }^{1,2}$, SEUNG YOUNG SEO ${ }^{1,2}$, SEONG HUN KIM ${ }^{1,2}$, IN HEE KIM ${ }^{1,2}$, \\ SEUNG OK LEE ${ }^{1,2}$, SOO TEIK LEE ${ }^{1,2}$, DAE-GHON KIM ${ }^{1,2}$ and SANG WOOK KIM ${ }^{1,2}$ \\ ${ }^{1}$ Department of Internal Medicine; ${ }^{2}$ Research Institute of Clinical Medicine, Chonbuk National University Hospital, \\ Chonbuk National University, Jeonju, Jeollabuk-do 561-712, Republic of Korea
}

Received April 22, 2014; Accepted January 13, 2015

DOI: $10.3892 / \mathrm{ol} .2015 .3017$

\begin{abstract}
Recently, the nuclear factor (NF)- $\kappa \mathrm{B}$ inhibitor parthenolide (PT) was identified as a promising anticancer agent for the promotion of cancer cell apoptosis. Additionally, our previous study demonstrated that PT administration suppresses tumor growth in a xenograft model of colorectal cancer cells via regulation of the B-cell lymphoma-2 (Bcl-2) family. However, the role of PT in the development of colitis-associated colon cancer (CAC) is poorly understood. Therefore, the aim of the present study was to investigate the effects of PT administration on CAC using a murine model. Azoxymethane (AOM) and dextran sulfate sodium (DSS) were administered to induce experimental CAC in the following three groups of treated mice: i) AOM and DSS plus vehicle; ii) AOM, DSS and $2 \mathrm{mg} / \mathrm{kg}$ PT; and iii) AOM, DSS and $4 \mathrm{mg} / \mathrm{kg}$ PT. It was demonstrated that the histological acuteness of AOM/DSS-induced CAC was significantly reduced following the administration of $\mathrm{PT}$, resulting in decreased NF- $\mathrm{B}$ p 65 expression levels via a blockade of phosphorylation and subsequent degradation of inhibitor of $\kappa \mathrm{B}-\alpha(\mathrm{I} \kappa \mathrm{B} \alpha)$. Furthermore, PT administration appeared to enhance the process of carcinogenesis via the downregulation of the antiapoptotic proteins Bcl-2 and Bcl-extra large, mediated by inhibition of $\mathrm{NF}-\kappa \mathrm{B}$ activation. Apoptosis and caspase-3 expression were markedly increased in the PT-treated group. These findings indicate that PT inhibits $\mathrm{I} \kappa \mathrm{B} \alpha$ phosphorylation and $\mathrm{NF}-\kappa \mathrm{B}$ activation, resulting in the initiation of apoptosis and the eventual suppression of CAC development. The beneficial effects of PT treatment observed
\end{abstract}

Correspondence to: Professor Sang Wook Kim, Department of Internal Medicine, Chonbuk National University Hospital, Chonbuk National University, 20 Geonji-ro, Jeonju-si, Jeollabuk-do 561-712, Republic of Korea

E-mail: clickm@jbnu.ac.kr

Key words: parthenolide, colitis-associated colon cancer, nuclear factor- $\kappa \mathrm{B}$, apoptosis in the experimental CAC model indicate the potential chemopreventive and therapeutic role of PT in CAC.

\section{Introduction}

The worldwide incidence of inflammatory bowel disease (IBD), namely ulcerative colitis (UC) and Crohn's disease, has been increasing for a number of decades. One possible explanation for this increase is that advances in treatment strategies have resulted in the prolonged survival of affected patients, however, the number of IBD patients diagnosed with colorectal cancer [CRC; colitis-associated cancer (CAC)] has also increased, particularly in those suffering from UC (1). $\mathrm{CAC}$ is considered to develop as a result of chronic inflammation, with a recently conducted meta-analysis estimating the incidence rate of $\mathrm{CAC}$ at 7 and 12 per 1,000 individuals per year in UC patients at 20 and 30 years post-diagnosis, respectively. This high incidence rate highlights the importance of preventing the development of CAC in high-risk UC patients (2). Furthermore, the expression of numerous inflammatory cytokines is associated with the development of acute or chronic intestinal inflammation (3-5); for example, the upregulation of the tumor necrosis factor- $\alpha$ (TNF- $\alpha$ ) and interleukin (IL)-1 $\beta$ pro-inflammatory cytokines requires the activation of transcription factor nuclear factor $\kappa B$ (NF-кB) (6-8).

Feverfew (Tanacetum parthenium), a traditional herb that has been applied medicinally in Europe for the treatment of migraine, fever and arthritis, contains a number of sesquiterpene lactones, including parthenolide (PT) (9). Previously conducted studies have established that the anti-inflammatory mechanisms of feverfew involve the inhibition of IL-1- and TNF- $\alpha$-mediated NF- $\kappa \mathrm{B}$ activation (10-12). PT was recently demonstrated to be the specific agent in feverfew that was responsible for this action, inhibiting $\mathrm{NF}-\kappa \mathrm{B}$ activation and thus inducing apoptotic cell death in various types of human cancer cells $(13,14)$. Additionally, previous studies have also demonstrated that PT is a potent inhibitor of $\mathrm{NF}-\kappa \mathrm{B}$ activation and can inhibit the expression of pro-inflammatory cytokines in experimental murine models (11,15-19). Our recent study used xenograft models to reveal that PT is a potential chemopreventive and therapeutic agent for CRC (20); however, to date, no evidence 
of the therapeutic effect of PT on CAC exists. Therefore, we hypothesized that $\mathrm{PT}$ exerts its anticarcinogenic effect on $\mathrm{CAC}$ by inhibiting the activation of the $N F-\kappa B$ signaling pathway. The present study aimed to provide experimental evidence of this hypothesis by evaluating the effect of PT administration on a murine model of azoxymethane (AOM)/dextran sulfate sodium (DSS)-induced CAC.

\section{Materials and methods}

Chemicals and reagents. Parthenolide and z-VAD-fluoromethylketone were obtained from Calbiochem (San Diego, CA, USA), AOM and DSS were purchased from Sigma-Aldrich (St. Louis, MO, USA) and a terminal deoxynucleotidyl transferase-mediated dUTP nick end-labeling (TUNEL) assay kit was obtained from Promega Corporation (Madison, WI, USA). Anti-inhibitor of $\kappa \mathrm{B} \alpha(\mathrm{I} \kappa \mathrm{B} \alpha$, mouse monoclonal; cat. no. sc-8404), anti-p65 (mouse monoclonal; cat. no. sc-8008), anti-B-cell lymphoma (Bcl)-2 (rabbit polyclonal; cat. no. sc-783), anti-Bcl-extra large (xL, mouse monoclonal; cat. no. sc-8392) and anti-caspase 3 (rabbit polyclonal; cat. no. sc-7148) antibodies were purchased from Santa Cruz Biotechnology, Inc. (Beverly, MA, USA), while anti-actin (rabbit polyclonal; cat. no. A2066) antibodies were purchased from Sigma-Aldrich.

Animal models. A total of 15 six-week-old pathogen-free female $\mathrm{Balb} / \mathrm{C}$ mice were purchased from Orient Bio Inc., (Seongnam, Korea). Mice were given ad libitum access to water and standard rodent food until they reached the desired weight (18-20 g). Mice were maintained on a 12-h:12-h light/dark cycle under specific pathogen free conditions. All procedures using the mice were reviewed and approved by Chonbuk National University Animal Care and Use Committee (Approval no: CBNU 20150013). In each group, five mice were randomly assigned after they were weighed. The mice were injected intraperitoneally with $7.4 \mathrm{mg} / \mathrm{kg}$ body weight of AOM dissolved in physiological saline. After five days, 3\% DSS was administered in the drinking water for five days, followed by 16 days of regular water. This cycle was repeated three times. Following sacrifice by cervical dislocation, the entire colon was removed from the cecum to the anus, and the colon was then opened longitudinally, and the number of macroscopic tumors were counted and measured using calipers. Subsequently, the distal colons were fixed in $10 \%$ neutral-buffered formalin for $24 \mathrm{~h}$, and transferred to $70 \%$ ethanol for subsequent paraffin embedding and histological analysis.

Histological analysis. The sections $(5 \mu \mathrm{m})$ were stained with hematoxylin and eosin, and histological analysis was performed by a pathologist in a double-blind manner. The inflammation scores of mucosal inflammation were determined as follows (21): 0, normal morphology; 1, focal inflammatory cell infiltrate around the crypt base; 2 , diffuse infiltration of inflammatory cells around the crypts or erosion/destruction of the lower one-third of the glands; and 3, erosion/destruction of the lower two-thirds of the glands or loss of all the glands. Furthermore, invasion depth was scored as follows (22): 0, no invasion; 1 , invasion through the mucosa; 2 , invasion through the submucosa; and 3, full invasion through the muscularis and into the serosa.
Immunohistochemistry (IHC). IHC was performed in paraffin-embedded, $5-\mu \mathrm{m}$ tissue sections. For the analysis

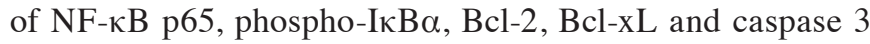
protein expression levels, the slides were hydrated and endogenous peroxidase activity quenched with $0.03 \%$ hydrogen peroxide in $\mathrm{MeOH}$. Antigen retrieval was performed using boiling sodium citrate in a microwave $(20 \mathrm{mM}$ sodium citrate $\mathrm{pH} 6.5$ ) for $16 \mathrm{~min}$ at $30 \%$ power. Subsequent to blocking, primary antibody was added (dilution ratio, 1:500) overnight at $4^{\circ} \mathrm{C}$. The slides were washed and incubated with secondary antibody for $30 \mathrm{~min}$. After this, the slides were reacted with streptavidin for $20 \mathrm{~min}$, the reaction was visualized with 3,3-diaminobenzidine tetrahydrochloride for $5 \mathrm{~min}$, and the slides were counterstained with Meyer's hematoxylin. Sections were examined under a Olympus BX53 microscope (Olympus America, Hauppauge, NY, USA); images of the representative areas were captured at a magnification of x20 and the number of positively stained cells were counted.

Apoptosis was quantitatively determined by performing a TUNEL assay using an ApopTag ${ }^{\circledR}$ in situ Apoptosis Detection kit (EMD Millipore, Temecula, CA, USA), according to the manufacturer's instructions. Four fields at x20 magnification were selected at the proliferation front of each tumor and the number of TUNEL-positive cells were counted.

Western blotting. Colon tissue samples were homogenized in lysis buffer [20 mM Tris $\mathrm{HCl}$ (pH 7.5), 1\% Triton X100, 0.2 M $\mathrm{NaCl}, 2$ mM EDTA, 2 mM ethylene glycol tetraacetic acid, $1 \mathrm{M}$ dithiothreitol and $2 \mathrm{M}$ aprotinin). Protein samples (50 $\mu \mathrm{g}$ per lane) were electrophoresed on 10\% SDS PAGE gels and the separated proteins were electrophoretically transferred onto polyvinylidene difluoride membranes. Subsequently, the membranes were incubated with anti-phospho IкB (1:1,000), anti-p65 (1:1,000), anti-Bcl2 $(1: 1,000)$, anti-Bcl-xL $(1: 1,000)$ and anti-caspase3 $(1: 1,000)$ and anti- $\beta$-actin $(1: 1,000)$ antibodies. The signal was detected using enhanced WEST-one (iNtRON Biotechnology, Daejeon, Korea) and analyzed with a luminescent image analyzer (LAS-3000; Fuji Film Corporation, Tokyo, Japan).

Statistical analysis. The data are presented as the mean \pm standard error of the mean of a minimum of three independent experiments performed in duplicate. Imaging analysis for IHC were performed by cellsense standard software (standard version, Olympus America). Representative blots are included. All data were entered into a Microsoft Excel version 5.0 (Microsoft Corporation, Redmond, WA, USA) spreadsheet, and SPSS software (SPSS, Inc., Chicago, IL, USA) was used to perform the two-tailed tests or the analysis of variance, where appropriate. $\mathrm{P}<0.05$ was considered to indicate a statistically significant difference.

\section{Results}

PT inhibits colon carcinogenesis induced by AOM/DSS administration in a murine model. AOM is a procarcinogen that upon metabolic activation, causes the formation of $\mathrm{O}^{6}$-methylguanine (23). AOM induces the development of tumors in the distal colon of rodents and is commonly used to elicit CRC in experimental animals (24-26). Thus, the present study used a CAC model in which six-week-old mice were injected with 
A

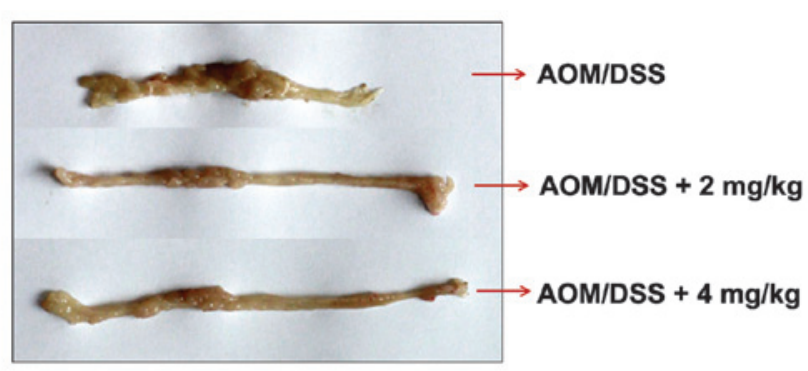

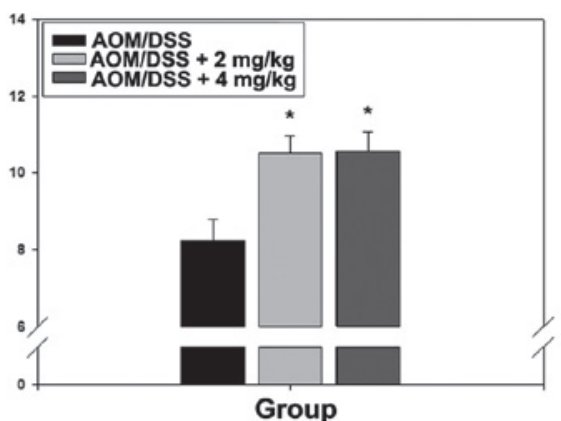

Group
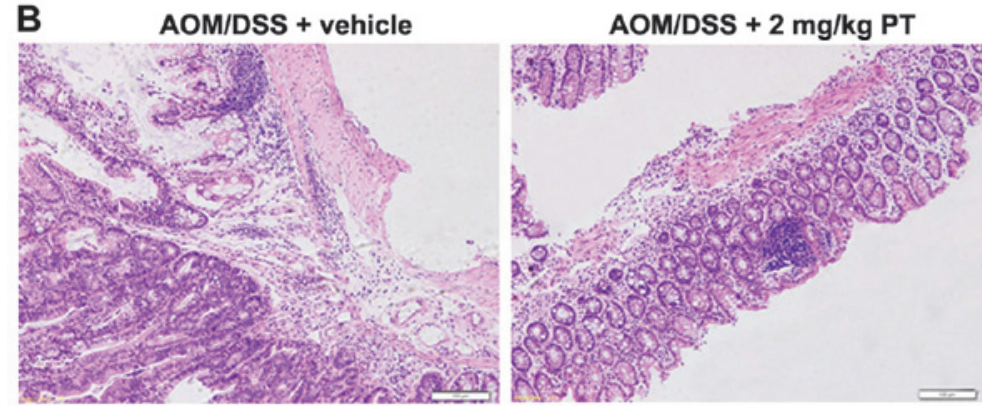

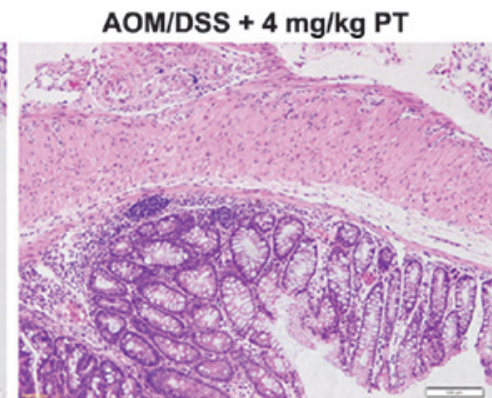

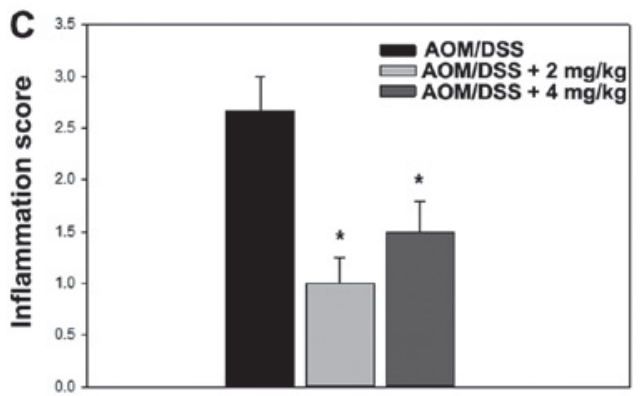

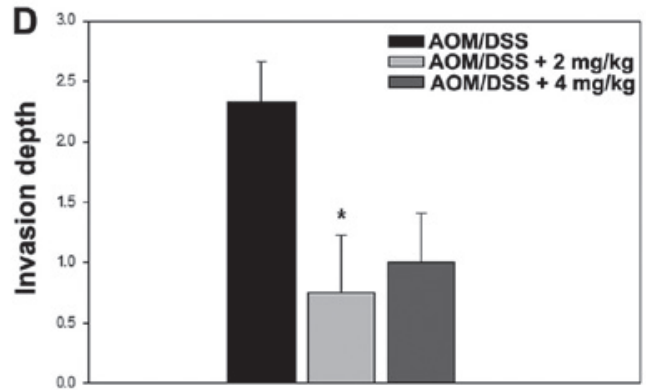

Figure 1. PT reduces colon carcinogenesis in a mouse model of colitis-associated cancer (CAC). (A) Representative images of the gross anatomy of the colon, indicating colon length upon termination of the CAC protocol. (B) Hematoxylin and eosin (H\&E) staining of colonic mucosal tissue section from CAC mice (magnification, x10). (C-D) Inflammation scores and invasion depth of H\&E-stained tissue specimens obtained from mice at the end of CAC induction, as determined by two pathologists in a blinded manner. " $\mathrm{P}<0.05$ vs. vehicle-treated group. AOM, azoxymethane; DSS, dextran sulfate sodium; PT, parthenolide.

a single dose of AOM followed by DSS administered in the drinking water to analyze the antitumor activities of PT. First, colon length was compared between the control (AOM/DSS plus DMSO as vehicle) and PT-treated (AOM/DSS plus $2 \mathrm{mg} / \mathrm{kg}$ PT and AOM/DSS plus $4 \mathrm{mg} / \mathrm{kg}$ PT) groups. Numerous nodular, polypoid and caterpillar-like tumors were observed in the middle and distal colon of mice in the control group. By contrast, shortening of the colon, which is a characteristic of colon carcinogenesis, was significantly improved in the PT-treated group (Fig. 1A). Histological analysis revealed that the severity of inflammation and the invasion depth of the ulcerated areas in the colons of the PT-treated mice were significantly lower compared with that in the non-PT-treated mice $(\mathrm{P}<0.05$; Fig. 1B-D).

Administration of $P T$ suppresses $N F-\kappa B$ signaling by blocking $I \kappa B \alpha$ phosphorylation. Degradation of I $\kappa$ B proteins via a phosphorylation and ubiquitination-dependent pathway is an essential step for NF- $\kappa \mathrm{B}$ activation (27). To evaluate the molecular basis of $\mathrm{NF}-\kappa \mathrm{B}$ inactivation by PT, the present study examined the effects of PT on the phosphorylation and degradation of $\mathrm{I} \kappa \mathrm{B} \alpha$ protein. As indicated in Fig. 2A, AOM/DSS mice treated with PT displayed significantly reduced phospho-I $\kappa \mathrm{B} \alpha$ positively-stained cells compared with the AOM/DSS control mice treated with vehicle. Furthermore, the protein expression level of phospho-I $\mathrm{B} \alpha$ was increased in the AOM/DSS-treated mice, but was markedly inhibited in the PT-treated mice (Fig. 2B).

Anti-NF- $\mathrm{B}$ p65 (RelA) is one of the subunits of $N F-\kappa B$ (27). Numerous anti-NF- $\kappa$ B p 65 positively-stained cells were detected in the mice with AOM/DSS-induced $\mathrm{CAC}$, whereas treatment with $\mathrm{PT}$ resulted in a significant reduction in the number of $\mathrm{NF}-\kappa \mathrm{B}$ p 65 positively-stained cells (Fig. 2A; $\mathrm{P}<0.05$ ). Furthermore, the protein expression level of NF- $\kappa$ B p 65 was markedly inhibited in the PT-treated mice and was highly correlated with the IHC results (Fig. 2B).

Administration of PT downregulates anti-apoptotic proteins $B c l-2$ and $B c l-x L$. The regulation of Bcl-2 and Bcl-xL expression by PT administration was examined in the CAC mice. As indicated in Fig. 3A, cells positively immunostained for Bcl-2 were detected in the AOM/DSS-induced CAC group; however, the number of Bcl-2 positively-immunostained cells was significantly reduced by $\mathrm{PT}$ treatment (Fig. $3 \mathrm{~A} ; \mathrm{P}<0.05$ ). Furthermore, the data correlated well with the western 

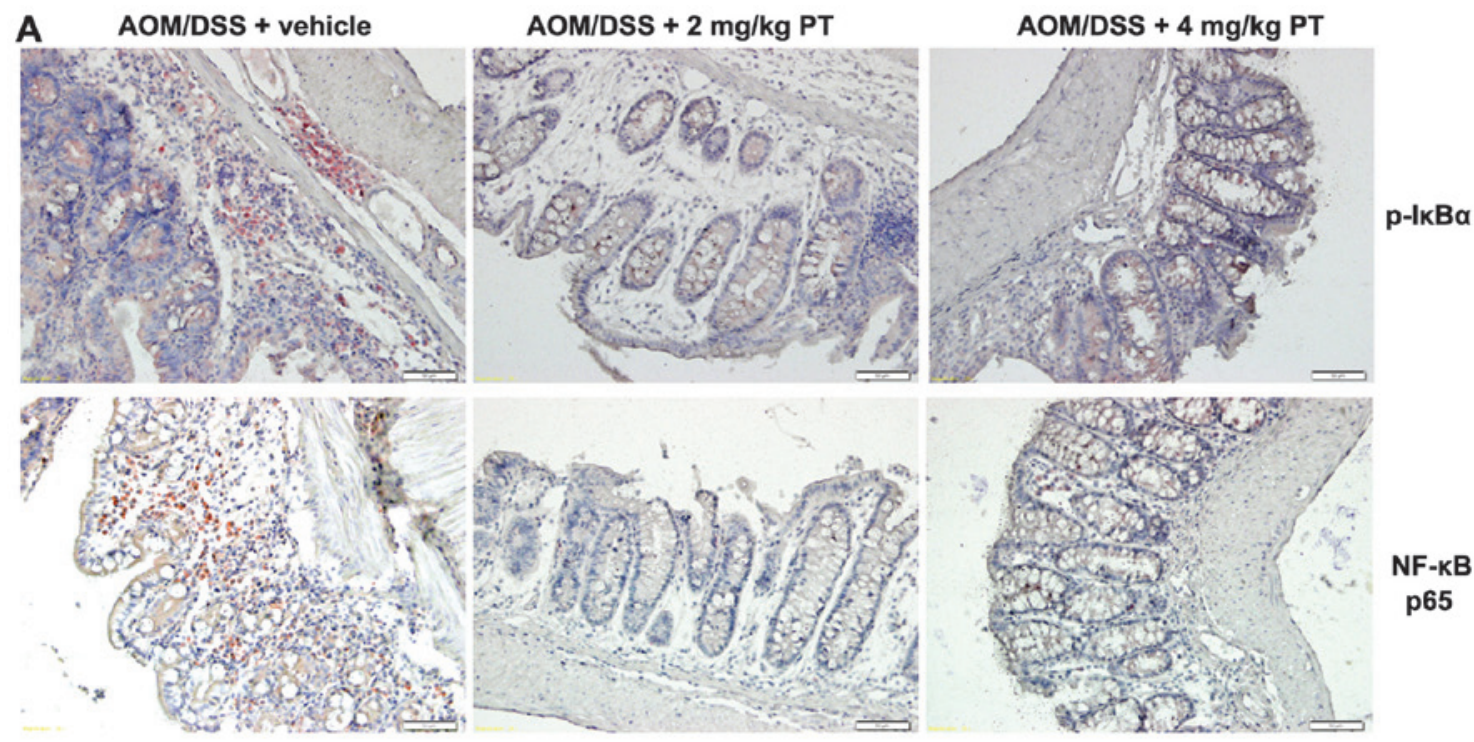

NF-KB

p65
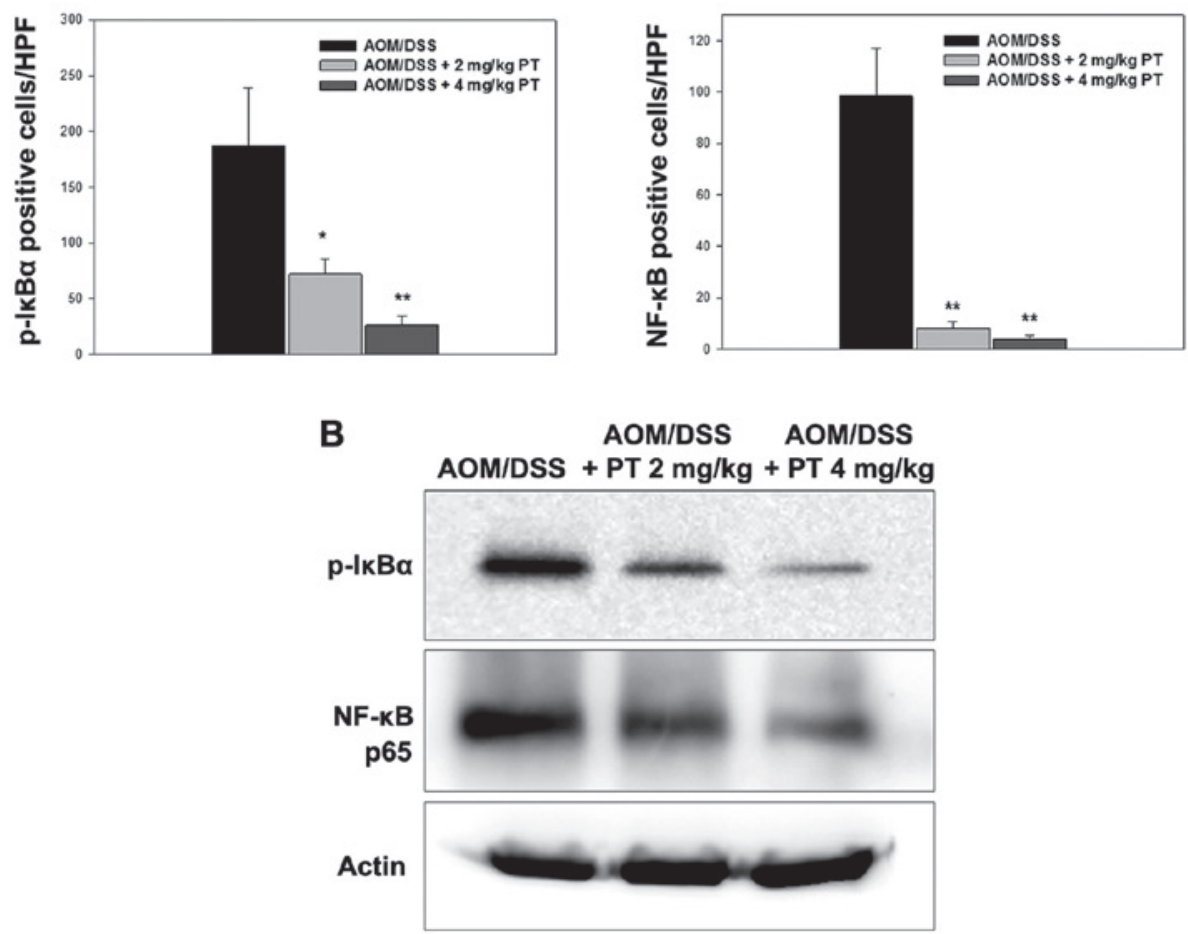

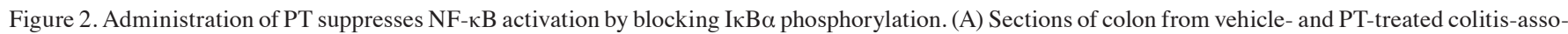
ciated cancer mice are stained with a p-IкB $\alpha$ or NF-kB p65 antibodies (magnification, $\mathrm{x} 20$ ). The number of positively-stained cells in the colon tissues was counted and represented as a graph. Error bars indicate the standard error of the mean. ${ }^{* *} \mathrm{P}<0.01$ vs. vehicle-treated group. (B) Western blot results demonstrate the protein expression levels of p-IкB $\alpha$ and NF- $\mathrm{kB}$ p65 in the colon tissues. Actin was used as the loading control. AOM, azoxymethane; DSS, dextran sulfate

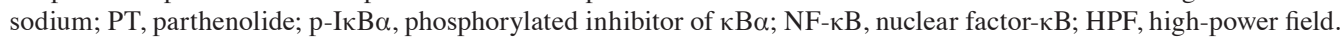

blotting results (Fig. 3B). Similarly, IHC with the Bcl-xL antibody resulted in markedly fewer positively-stained cells in the PT-treated group compared with the vehicle-treated group (Fig. 3A), and Bcl-xL protein expression levels were significantly downregulated following PT treatment (Fig. 3A; $\mathrm{P}<0.05)$.

Administration of PT increases apoptosis in dysplasia lesions in a murine CAC model. To perform additional evaluation of the effects of PT on apoptosis, caspase 3 expression was examined by IHC, and apoptotic cells were detected in the colonic epithelium using a TUNEL assay. The results revealed that the number of cells positively stained with caspase 3 and TUNEL (Fig. 4) was significantly increased in the two PT-treated groups compared with the vehicle-treated group, indicating that PT promotes apoptosis in the colons of CAC mice.

\section{Discussion}

Our previous study demonstrated that PT induces apoptosis in a number of human CRC cell lines, including the HT-29, LS174T and SW480 cell lines, and that it reduces tumor growth and 
A AOM/DSS + vehicle

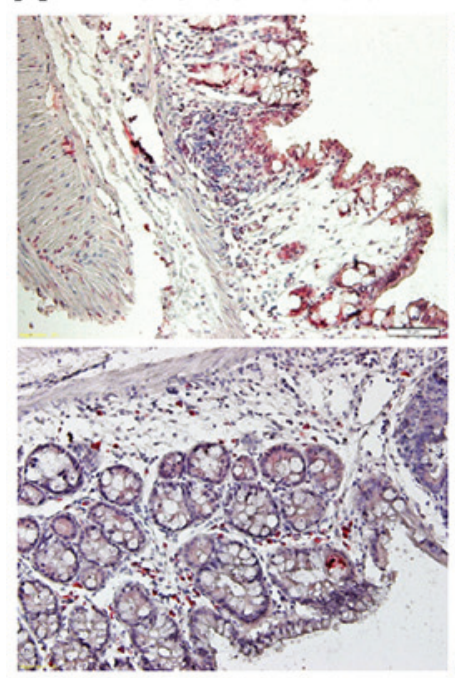

AOM/DSS + $2 \mathrm{mg} / \mathrm{kg}$ PT
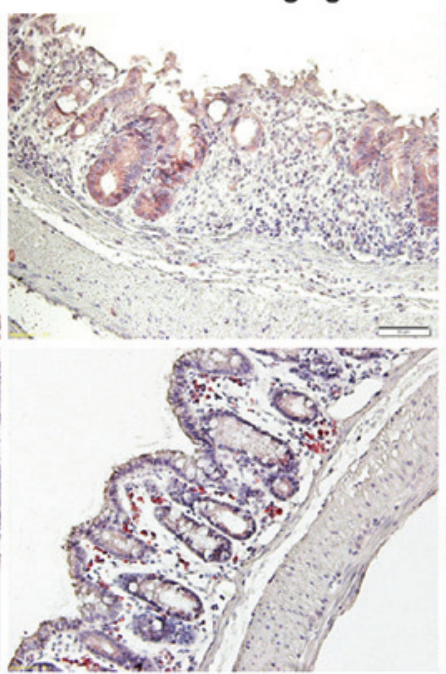

AOM/DSS + $4 \mathrm{mg} / \mathrm{kg}$ PT

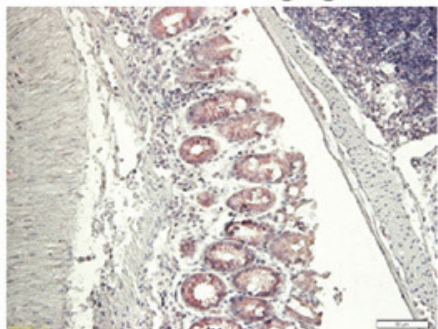

Bcl-2

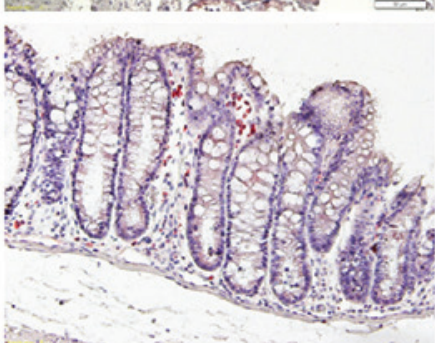

Bcl-XL
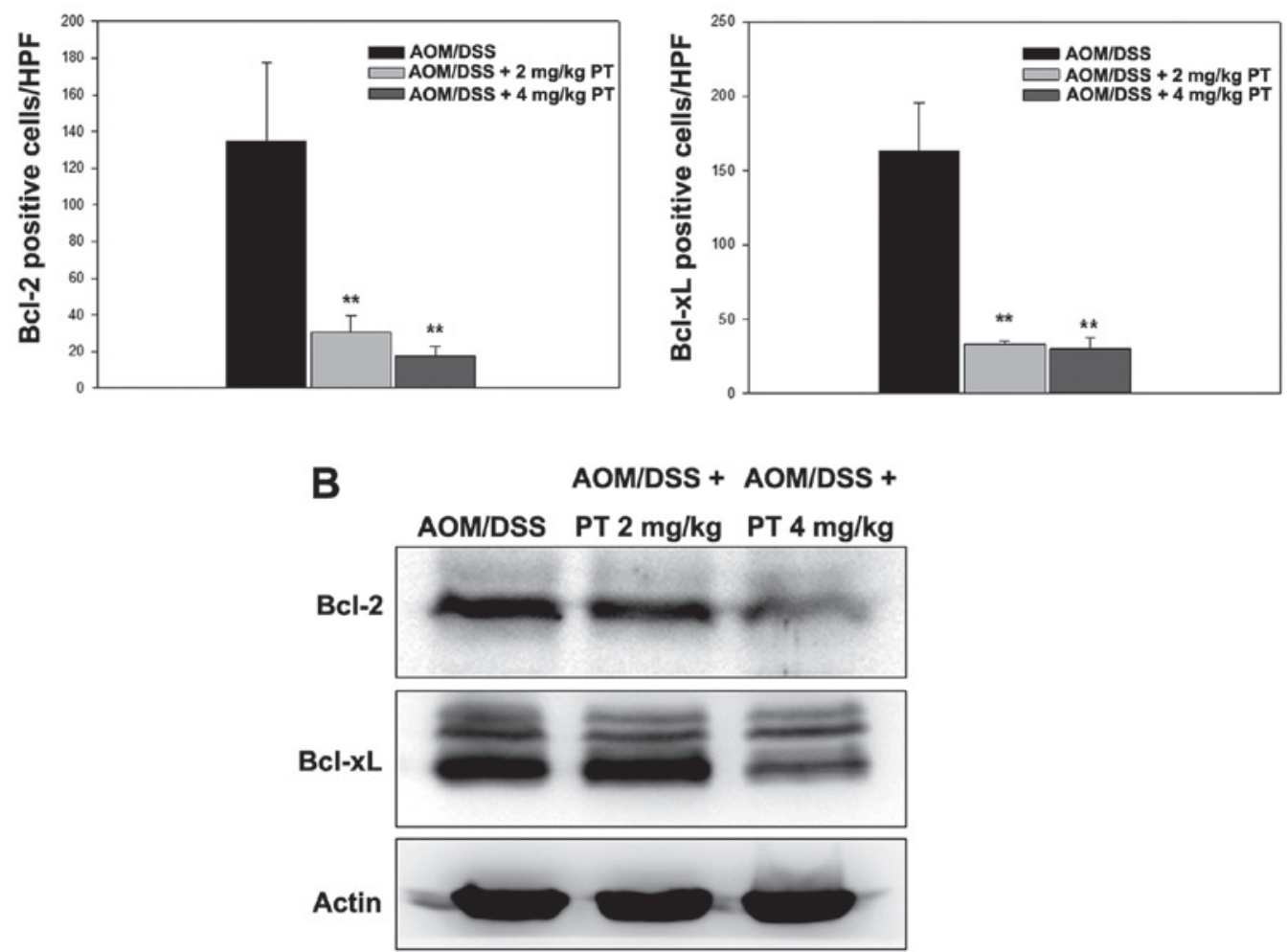

Figure 3. Administration of PT downregulates anti-apoptotic proteins. (A) Sections of colon from vehicle- and PT-treated colitis-associated cancer mice are stained with a Bcl-2 or Bcl-xL antibodies (magnification, x20). The number of positively-stained cells in the colon tissue was counted and represented as a graph. Error bars indicate the standard error of the mean. ${ }^{* *} \mathrm{P}<0.01$ vs. vehicle-treated group. (B) Western blotting results demonstrate the protein expression levels of p-IкB $\alpha$ and NF-кB p65 in the colon tissues. Actin was used as the loading control. AOM, azoxymethane; DSS, dextran sulfate sodium; PT, partheno-

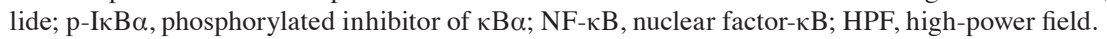

angiogenesis in a CRC xenograft model (28). PT is considered to be a promising candidate as a novel type of chemotherapeutic agent for cancer treatment; however, to the best of our knowledge, no study has yet explained the mechanism of the anticancer effect of PT on CAC. Therefore, the present study selected an AOM/DSS mouse model to assess the role of PT in $\mathrm{CAC}$ and in $\mathrm{NF}-\kappa \mathrm{B}$ inactivation. In agreement with our hypothesis, the results indicated that PT administration clinically and histologically improves AOM/DSS-induced CAC in mice, as assessed by histological injury scores. Furthermore, the beneficial effect of PT treatment appears to inhibit NF- $\kappa \mathrm{B}$ activation via blocking $\mathrm{I} \kappa \mathrm{B} \alpha$ phosphorylation and is associated with the downregulation of the apoptosis-associated molecules, Bcl-2, Bcl-xL and caspase 3. These findings indicate that PT may be a useful therapeutic approach to treat CAC and that PT may block I $\mathrm{B} \alpha$ phosphorylation, thus silencing $\mathrm{NF}-\kappa \mathrm{B}$ activation.

The oncogenic potential of AOM is markedly augmented in the setting of chronic inflammation, such as that induced by repeated cycles of DSS treatment (29). A recent study 

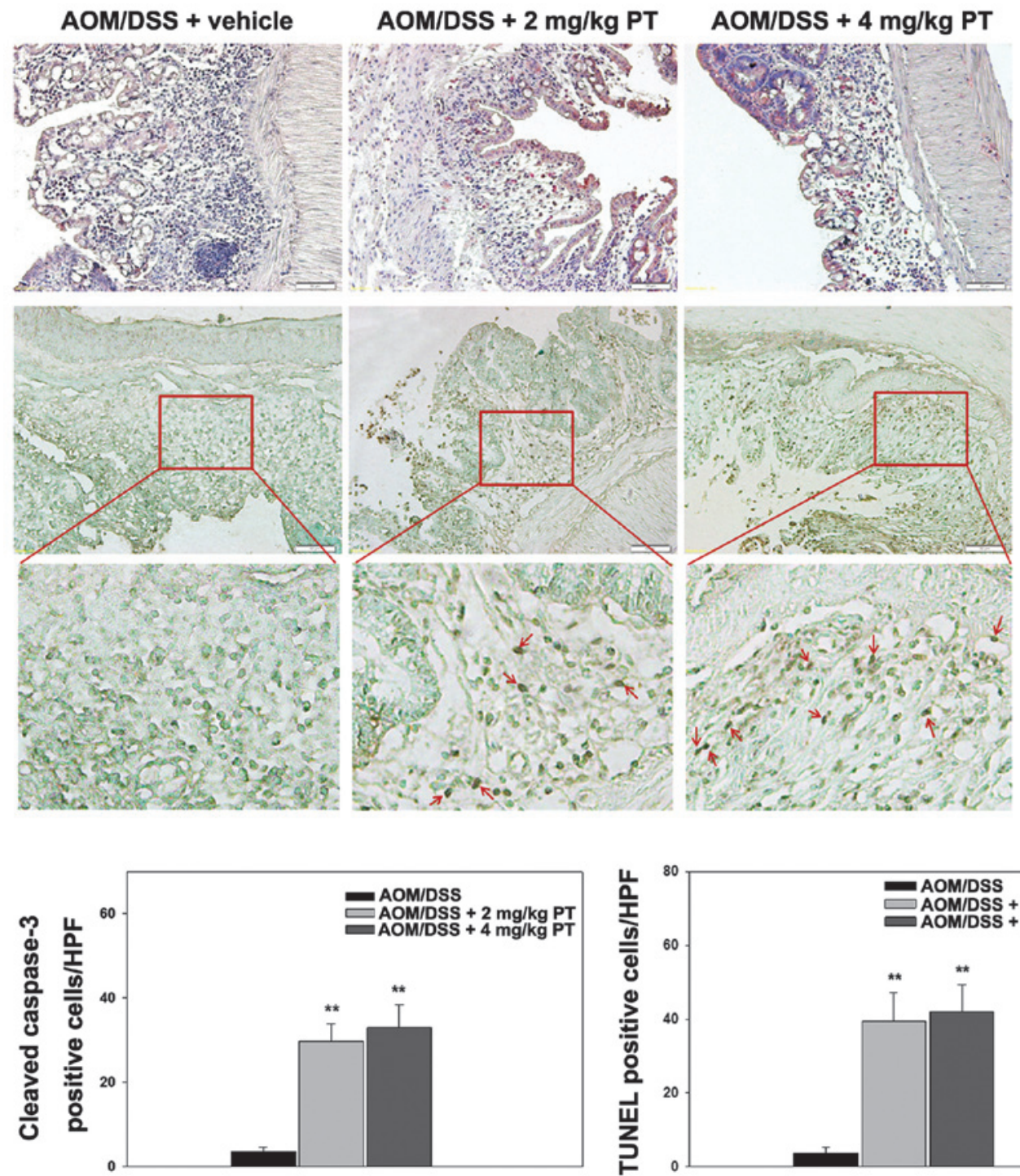

\section{Cleaved \\ caspase-3}

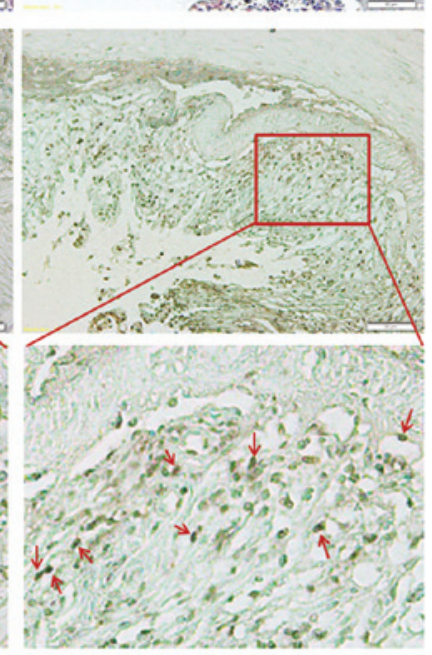

TUNEL

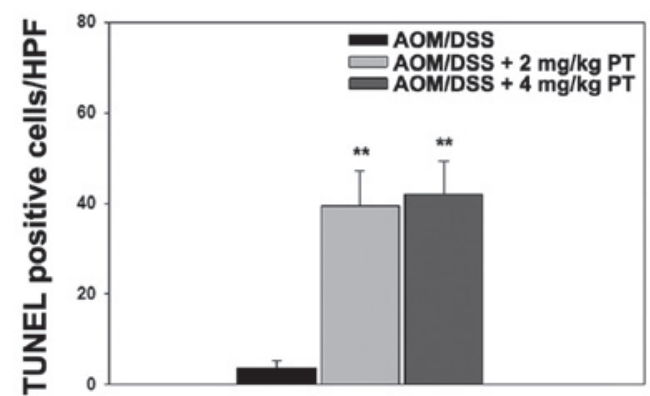

Figure 4. Administration of PT increases apoptosis in dysplasia lesions in colitis-associated cancer mice. Sections of colon from vehicle- and PT-treated mice are stained with caspase 3 antibody and analyzed using TUNEL (magnification, x20). Red arrows indicate TUNEL positively-stained cells. The number of positively-stained cells in the colon tissue was counted and represented as a graph. Error bars indicate the standard error of the mean. ${ }^{* *} \mathrm{P}<0.01 \mathrm{vs}$. vehicle-treated group. AOM, azoxymethane; DSS, dextran sulfate sodium; PT, parthenolide; TUNEL, terminal deoxynucleotidyl transferase-mediated dUTP nick end-labeling assay; HPF, high-power field.

demonstrated the power of this model by deciphering the epithelial versus myeloid cell contribution of ІкB kinase $\beta$ to polyp formation in the setting of inflammation (30), while a different study investigated the contributions of IL-6 and its downstream mediator, signal transducer and activator of transcription-3 (STAT-3) (31). PT is an effective inhibitor of IL-6-type cytokines, which activate the phosphorylation of STAT3 on Tyr 705. PT has been demonstrated to prevent the activity of IL-6-type cytokines by inhibiting the phosphorylation of STAT3 on Tyr $705(32,33)$, indicating that PT, as an inhibitor of IL-6, is able to provide protection from carcinogenesis in experimental CAC models. Although the present study did not demonstrate the role of PT in regulating and suppressing carcinogenesis via the IL-6/STAT3 pathway, additional important insights into the mechanism were obtained.

Previous studies have demonstrated that NF- $\mathrm{kB}$, a central molecule involved in inflammation, regulates the expression of a diverse array of target genes that are involved in promoting cell proliferation, regulating immune and inflammatory responses and contributing towards the pathogenesis of various diseases, including cancer (34-36). In chronic inflammation, NF- $\mathrm{kB}$ has a specific role in coupling inflammation to cancer. In total, $>15 \%$ of all malignancies are initiated by chronic inflammatory disease; for example, skin inflammation initiates squamous cell carcinoma, viral hepatitis initiates liver cancer and inflammatory bowel disease (IBD) initiates CRC (31,37-41). Previous studies have indicated that constitutive NF- $\mathrm{kB}$ activation in IBDs may be the cause of the increased risk of developing CRC (42-44). It has been shown that PT is a potent inhibitor of NF- $\mathrm{KB}$ activation, which is able to effectively inhibit pro-inflammatory cytokine expression in cultured cells and experimental models $(11,15-19,45)$. Furthermore, a previous study using experimental murine colitis demonstrated that the administration of PT significantly reduces the severity of DSS-induced colitis,

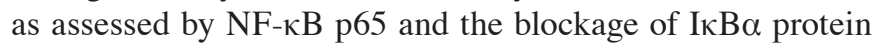


phosphorylation, and resulting in a reduction in the expression of inflammatory mediators, including myeloperoxidase activity, TNF- $\alpha$ and IL-1 $\beta$ (46). The present study has demonstrated that PT suppresses I $\mathrm{B} \alpha$ phosphorylation and $\mathrm{NF}-\kappa \mathrm{B}$ p 65 in a CAC mouse model, providing experimental evidence of the potential application of $\mathrm{PT}$ in CAC patients.

The association between NF- $\mathrm{KB}$ and apoptosis was recently elucidated in studies demonstrating that the inhibition of $\mathrm{NF}-\kappa \mathrm{B}$ activation, by the $\mathrm{I} \kappa \mathrm{B}$ super repressor $(47,48)$ or in Rel A (p65) knock-out cells (49), results in increased apoptosis. In particular, $\mathrm{NF}-\kappa \mathrm{B}$ appears to be responsible for the activation of genes involved in proliferation and tumor survival, such as those of the apoptotic proteins $\mathrm{Bcl}-2$ and $\mathrm{Bcl}-\mathrm{xL}(50,51)$. The results of the present study indicated that PT is essential for AOM/DSS-induced colon cancer carcinogenesis via the apoptotic route-associated Bcl-2 family members, which cause inhibition of NF- $\kappa \mathrm{B}$ activation. Additionally, the PT-treated cells appeared to undergo greater levels of apoptosis compared with the vehicle-treated group, as evaluated by caspase 3 antibody staining and TUNEL assay. Thus, the present study indicates that NF- $\kappa \mathrm{B}$ is the key regulator of PT-mediated apoptosis via the apoptosis signaling cascade.

In conclusion, the present study demonstrated that the administration of PT appears to significantly inhibit the inflammation-carcinoma sequence and may be a crucial regulator of experimental CAC. Possibly via the negative regulation of $\mathrm{NF}-\kappa \mathrm{B}, \mathrm{PT}$ reduces $\mathrm{I} \kappa \mathrm{B} \alpha$ phosphorylation, and $\mathrm{Bcl}-2$ and $\mathrm{Bcl}-\mathrm{xL}$ expression, increases the expression of caspase 3 , and promotes cell apoptosis, resulting in the suppression of tumorigenesis. Therefore, PT may be a novel chemopreventive agent for the treatment of CAC.

\section{Acknowledgements}

The present study was supported by the 18th grant from the Kye-Nam, Kim Jae Jung Memorial Fund. The authors thank Professor Mie-Jae Im for proofreading the original manuscript and for all contributions.

\section{References}

1. Podolsky DK: Inflammatory bowel disease. N Engl J Med 347: 417-429, 2002

2. Eaden JA, Abrams KR and Mayberry JF: The risk of colorectal cancer in ulcerative colitis: a meta-analysis. Gut 48: 526-535, 2001.

3. Papadakis KA and Targan SR: Role of cytokines in the pathogenesis of inflammatory bowel disease. Annu Rev Med 51: 289-298, 2000.

4. Rogler G and Andus T: Cytokines in inflammatory bowel disease. World J Surg 22: 382-389, 1998.

5. Neurath MF, Fuss I, Schürmann G, et al: Cytokine gene transcription by NF-kappa B family members in patients with inflammatory bowel disease. Ann NY Acad Sci 859: 149-159, 1998

6. Blackwell TS and Christman JW: The role of nuclear factor-kappa B in cytokine gene regulation. Am J Respir Cell Mol Biol 17: 3-9, 1997.

7. Baeuerle PA and Henkel T: Function and activation of NF-kappa B in the immune system. Annu Rev Immunol 12: 141-179, 1994.

8. Baldwin AS Jr: The NF-kappa B and I kappa B proteins: new discoveries and insights. Annu Rev Immunol 14: 649-683, 1996.

9. Knight DW: Feverfew: chemistry and biological activity. Nat Prod Rep 12: 271-276, 1995.

10. Murphy JJ, Heptinstall S and Mitchell JR: Randomised double-blind placebo-controlled trial of feverfew in migraine prevention. Lancet 2: 189-192, 1988.
11. Hehner SP, Heinrich M, Bork PM, et al: Sesquiterpene lactones specifically inhibit activation of NF-kappa B by preventing the degradation of I kappa B-alpha and I kappa B-beta. J Biol Chem 273: 1288-1297, 1998.

12. Lyss G, Knorre A, Schmidt TJ, Pahl HL and Merfort I: The anti-inflammatory sesquiterpene lactone helenalin inhibits the transcription factor NF-kappaB by directly targeting p65. J Biol Chem 273: 33508-33516, 1998

13. Zhang S, Ong CN and Shen HM: Critical roles of intracellular thiols and calcium in parthenolide-induced apoptosis in human colorectal cancer cells. Cancer Lett 208: 143-153, 2004.

14. Wen J, You KR, Lee SY, Song CH and Kim DG: Oxidative stress-mediated apoptosis. The anticancer effect of the sesquiterpene lactone parthenolide. J Biol Chem 277: 38954-38964, 2002.

15. Sweeney CJ, Mehrotra S, Sadaria MR, et al: The sesquiterpene lactone parthenolide in combination with docetaxel reduces metastasis and improves survival in a xenograft model of breast cancer. Mol Cancer Ther 4: 1004-1012, 2005.

16. Saadane A, Masters S, DiDonato J, Li J and Berger M: Parthenolide inhibits IkappaB kinase, NF-kappaB activation, and inflammatory response in cystic fibrosis cells and mice. Am J Respir Cell Mol Biol 36: 728-736, 2007.

17. Miyata N, Gon Y, Nunomura S, et al: Inhibitory effects of parthenolide on antigen-induced microtubule formation and degranulation in mast cells. Int Immunopharmacol 8: 874-880, 2008.

18. Hehner SP, Hofmann TG, Dröge W and Schmitz ML: The antiinflammatory sesquiterpene lactone parthenolide inhibits NF-kappa B by targeting the I kappaB kinase complex. J Immunol 163: 5617-5623, 1999.

19. Kwok BH, Koh B, Ndubuisi MI, et al: The anti-inflammatory natural product parthenolide from the medicinal herb Feverfew directly binds to and inhibits IkappaB kinase. Chem Biol 8: 759-766, 2001.

20. Kim SL, Trang KT, Kim SH, et al: Parthenolide suppresses tumor growth in a xenograft model of colorectal cancer cells by inducing mitochondrial dysfunction and apoptosis. Int J Oncol 41: 1547-1553, 2012.

21. Wang Y, Zhang HX, Sun YP, et al: Rig-I-/- mice develop colitis associated with downregulation of G alpha i2. Cell Res 17: 858-868, 2007.

22. Arthur JC, Perez-Chanona E, Mühlbauer M, et al: Intestinal inflammation targets cancer-inducing activity of the microbiota. Science 338: 120-123, 2012

23. Pegg AE: Methylation of the O6 position of guanine in DNA is the most likely initiating event in carcinogenesis by methylating agents. Cancer Invest 2: 223-231, 1984.

24. Popivanova BK, Kitamura K, Wu Y, et al: Blocking TNF-alpha in mice reduces colorectal carcinogenesis associated with chronic colitis. J Clin Invest 118: 560-570, 2008.

25. Tanaka T, Suzuki R, Kohno H, et al: Colonic adenocarcinomas rapidly induced by the combined treatment with 2-amino-1-methyl-6-phenylimidazo [4,5-b]pyridine and dextran sodium sulfate in male ICR mice possess beta-catenin gene mutations and increases immunoreactivity for beta-catenin, cyclooxygenase-2 and inducible nitric oxide synthase. Carcinogenesis 26: 229-238, 2005.

26. Kohno H, Suzuki R, Sugie S and Tanaka T: Beta-Catenin mutations in a mouse model of inflammation-related colon carcinogenesis induced by 1,2-dimethylhydrazine and dextran sodium sulfate. Cancer Sci 96: 69-76, 2005.

27. Hayden MS and Ghosh S: Shared principles in NF-kappaB signaling. Cell 132: 344-362, 2008.

28. Kim SL, Trang KT, Kim SH, et al: Parthenolide suppresses tumor growth in a xenograft model of colorectal cancer cells by inducing mitochondrial dysfunction and apoptosis. Int J Oncol 41: 1547-1553, 2012.

29. Okayasu I, Ohkusa T, Kajiura K, et al: Promotion of colorectal neoplasia in experimental murine ulcerative colitis. Gut 39: 87-92, 1996.

30. Greten FR, Eckmann L, Greten TF, et al: IKKbeta links inflammation and tumorigenesis in a mouse model of colitis-associated cancer. Cell 118: 285-296, 2004.

31. Grivennikov S, Karin E, Terzic J, et al: IL-6 and Stat3 are required for survival of intestinal epithelial cells and development of colitis-associated cancer. Cancer Cell 15: 103-113, 2009.

32. Sobota R, Szwed M, Kasza A, et al: Parthenolide inhibits activation of signal transducers and activators of transcription (STATs) induced by cytokines of the IL-6 family. Biochem Biophys Res Commun 267: 329-333, 2000. 
33. SongJM,QianX,UpadhyayyaP,etal:Dimethylaminoparthenolide, a water soluble parthenolide, suppresses lung tumorigenesis through down-regulating the STAT3 signaling pathway. Curr Cancer Drug Targets 14: 59-69, 2014.

34. Luo JL, Kamata $\mathrm{H}$ and Karin M: IKK/NF-kappaB signaling: balancing life and death - a new approach to cancer therapy. J Clin Invest 115: 2625-2632, 2005.

35. Hayden MS and Ghosh S: Signaling to NF-kappaB. Genes Dev 18: 2195-2224, 2004.

36. Karin $M$ and Ben-Neriah $Y$ : Phosphorylation meets ubiquitination: the control of NF-[kappa]B activity. Annu Rev Immunol 18: 621-663, 2000.

37. Coussens LM and Werb Z: Inflammation and cancer. Nature 420 : 860-867, 2002.

38. Lawrence T, Willoughby DA and Gilroy DW: Anti-inflammatory lipid mediators and insights into the resolution of inflammation. Nat Rev Immunol 2: 787-795, 2002.

39. Vakkila $J$ and Lotze MT: Inflammation and necrosis promote tumour growth. Nat Rev Immunol 4: 641-648, 2004.

40. Schottenfeld D and Beebe-Dimmer J: Chronic inflammation: a common and important factor in the pathogenesis of neoplasia. CA Cancer J Clin 56: 69-83, 2006.

41. Schottenfeld D and Beebe-Dimmer JL: Advances in cancer epidemiology: understanding causal mechanisms and the evidence for implementing interventions. Annu Rev Public Health 26: 37-60, 2005.

42. Neurath MF, Pettersson S, Meyer zum Büschenfelde KH and Strober W: Local administration of antisense phosphorothioate oligonucleotides to the p65 subunit of NF-kappaB abrogates established experimental colitis in mice. Nat Med 2: 998-1004, 1996.

43. Rogler G, Brand K, Vogl D, Page S, Hofmeister R, et al: Nuclear factor kappaB is activated in macrophages and epithelial cells of inflamed intestinal mucosa. Gastroenterology 115 : 357-369, 1998.
44. Ardite E, Panés J, Miranda M, et al: Effects of steroid treatment on activation of nuclear factor kappaB in patients with inflammatory bowel disease. Br J Pharmacol 124: 431-433, 1998.

45. Kang BY, Chung SW and Kim TS: Inhibition of interleukin-12 production in lipopolysaccharide-activated mouse macrophages by parthenolide, a predominant sesquiterpene lactone in Tanacetum parthenium: involvement of nuclear factor-kappaB. Immunol Lett 77: 159-163, 2001.

46. Zhao ZJ, Xiang JY, Liu L, Huang XL and Gan HT: Parthenolide, an inhibitor of the nuclear factor- $\mathrm{KB}$ pathway, ameliorates dextran sulfate sodium-induced colitis in mice. Int Immunopharmacol 12: 169-174, 2012.

47. Wang CY, Mayo MW and Baldwin AS Jr: TNF- and cancer therapy-induced apoptosis: potentiation by inhibition of NF-kappaB. Science 274: 784-787, 1996.

48. Van Antwerp DJ, Martin SJ, Kafri T, Green DR and Verma IM: Suppression of TNF-alpha-induced apoptosis by NF-kappaB. Science 274: 787-789, 1996.

49. Beg AA and Baltimore D: An essential role for NF-kappaB in preventing TNF-alpha-induced cell death. Science 274: 782-784, 1996.

50. Wang YW, Wang SJ, Zhou YN, Pan SH and Sun B: Escin augments the efficacy of gemcitabine through down-regulation of nuclear factor- $\kappa \mathrm{B}$ and nuclear factor- $\kappa \mathrm{B}$-regulated gene products in pancreatic cancer both in vitro and in vivo. J Cancer Res Clin Oncol 138: 785-797, 2012.

51. Sun JG, Chen CY, Luo KW, et al: 3,5-Dimethyl-H-furo[3,2-g] chromen-7-one as a potential anticancer drug by inducing p53-dependent apoptosis in human hepatoma HepG2 cells. Chemotherapy 57: 162-172, 2011. 